\title{
Non-steroidal anti-inflammatory drug- induced enteropathy as a major risk factor for small bowel bleeding: a retrospective study
}

Doo-Ho Lim ${ }^{1 \dagger}$, Kyoungwon Jung ${ }^{2+}$, Seung Bum Lee ${ }^{1 *}$, In Kyu Park ${ }^{3}$, Hee Jeong Cha ${ }^{4}$, Jae Ho Park', Byung Gyu Kim', Seok Won Jung ${ }^{1}$, In Du Jeong ${ }^{1}$, Jae Hyun Kim², Sung Eun Kim², Won Moon², Moo In Park ${ }^{2}$ and Seun Ja Park ${ }^{2}$

\begin{abstract}
Background: Small bowel (SB) bleeding accounts for 5\% of all gastrointestinal (GI) bleeding cases and 80\% of obscure Gl bleeding cases. Although angioectasia is the common etiology of SB bleeding, nonsteroidal anti-inflammatory drug (NSAID)-induced SB lesions are also reported as a major cause in studies from Eastern countries. Herein, we assessed the frequency of occurrence of NSAID-induced SB lesions in Korean patients with obscure GI bleeding.

Methods: We retrospectively analyzed medical records of all consecutive patients aged $\geq 18$ years who underwent capsule endoscopy from March 2018 to February 2019 at Ulsan University Hospital and Kosin University Gospel Hospital.

Results: Of the 83 subjects (all Korean; mean age \pm standard deviation: $59 \pm 18$ years; age range: 18-84 years; men: $n=52$; women: $n=31), 55$ (66.2\%) had stool with clear blood and 28 (33.8\%) had normal stool with iron deficiency anemia. The detection rate of SB bleeding and lesions using capsule endoscopy was $72.3 \%$ (60 of 83 patients). A significantly higher frequency (40 of 51) of ulcerative/erosive lesions than other causes was observed in patients with inactive bleeding but visible SB lesions. As a result, NSAID-induced enteropathy accounted for $30.1 \%$ of 83 patients with obscure Gl bleeding (25 of the all 60 SB bleeding cases).

Conclusions: Contrary to what is reported for patients in Western countries, this study in Korean patients showed an improved diagnostic yield of capsule endoscopy for obscure Gl bleeding and that NSAID-induced enteropathy was the most common etiology of SB bleeding. Aggressive small intestine examination is required for patients with unexplained Gl bleeding.
\end{abstract}

Keywords: Capsule endoscopy, Nonsteroidal anti-inflammatory drugs, Obscure gastrointestinal bleeding, Iron deficiency anemia, Angioectasia

\footnotetext{
* Correspondence: sblee@uuh.ulsan.kr

${ }^{\dagger}$ Doo-Ho Lim and Kyoungwon Jung share co-first authorship

'Department of Internal Medicine, University of Ulsan College of Medicine,

Ulsan University Hospital, 877 Bangeojinsunhwando-ro, Dong-gu, Ulsan

44033, South Korea

Full list of author information is available at the end of the article
}

(c) The Author(s). 2020 Open Access This article is licensed under a Creative Commons Attribution 4.0 International License, which permits use, sharing, adaptation, distribution and reproduction in any medium or format, as long as you give appropriate credit to the original author(s) and the source, provide a link to the Creative Commons licence, and indicate if changes were made. The images or other third party material in this article are included in the article's Creative Commons licence, unless indicated otherwise in a credit line to the material. If material is not included in the article's Creative Commons licence and your intended use is not permitted by statutory regulation or exceeds the permitted use, you will need to obtain permission directly from the copyright holder. To view a copy of this licence, visit http://creativecommons.org/licenses/by/4.0/ The Creative Commons Public Domain Dedication waiver (http://creativecommons.org/publicdomain/zero/1.0/) applies to the data made available in this article, unless otherwise stated in a credit line to the data. 


\section{Background}

Obscure gastrointestinal (GI) bleeding is defined as persistent or recurrent bleeding of unknown origin despite repetitive diagnostic testing, including upper GI endoscopy and colonoscopy [1]. Small bowel (SB) bleeding accounts for $80 \%$ of obscure GI bleeding cases and $5 \%$ of all GI bleeding cases. Unexplained iron deficiency anemia (IDA) manifests in $30-40 \%$ of obscure GI bleeding cases [2]. Capsule endoscopy is the first-line examination in cases of obscure GI bleeding and the third diagnostic test after negative upper and lower endoscopy results in cases of ongoing overt bleeding [3-6]. Whereas angioectasia is the most common etiology of SB bleeding in Western countries $[4,7,8]$, nonsteroidal anti-inflammatory drug (NSAID)-induced SB lesions are the major cause reported in Japanese studies $[9,10]$.

NSAIDs are widely prescribed in most clinical conditions; however, it is well known that these drugs can cause GI complications [11]. Although various studies have reported an association between NSAID intake and GI adverse effects [12, 13], the role of NSAIDs in SB bleeding remains to be elucidated. Therefore, we aimed to assess the frequency of NSAID-induced SB lesions in Korean patients with obscure GI bleeding, who underwent capsule endoscopy.

\section{Methods}

\section{Study population}

We retrospectively evaluated the medical records of all consecutive patients aged $\geq 18$ years with obscure GI bleeding who underwent capsule endoscopy from March 2018 to February 2019 at Ulsan University Hospital and Kosin University Gospel Hospital. The indication for the test included bloody stool in patients with an unidentified source of bleeding and lesions during diagnostic evaluations, including upper GI endoscopy, colonoscopy, and abdominal computed tomography (CT) in the last 3 months [5]. We also included patients who had no visible bloody stool, showed persistent or repeated exacerbation of IDA despite iron supplementation for $>6$ months, and had no hemorrhagic lesions identified during the above screening methods in the last 3 months [14]. If CT-scan had been performed in the last 1 year, in some patients, the test was not performed again when anemia was confirmed. Rebleeding was defined as recurrent anemia ( $\geq 2 \mathrm{~g} / \mathrm{dL}$ decrease in the hemoglobin level), overt melena/ hematochezia, or occult GI bleeding during the follow-up period [15]. This study was approved by the Institutional Review Boards (IRB of the Ulsan University Hospital (IRB No. 2019-10-014) and the Kosin University Gospel Hospital (IRB No. 2019-10001)). The requirement for informed consent from patients was waived because patient records and information were de-identified prior to analysis.

\section{Capsule endoscopy}

Capsule endoscopy was performed using Pillcam ${ }^{\bullet}$ (SB3, Given Imaging Ltd., Yoqneam, Israel) and MiroCam ${ }^{\circ}$ (MC1200, IntroMedic Ltd., Seoul, Korea) devices. Given that both pieces of equipment have $12 \mathrm{~h}$ of battery life, all endoscopies were performed for $12 \mathrm{~h}$. All patients fasted for $12 \mathrm{~h}$ and received $40 \mathrm{mg}$ of oral simethicone before the procedure to prevent air bubbles from forming [16]. Moreover, we used $2 \mathrm{~L}$ polyethylene glycol solution at least $2-16 \mathrm{~h}$ before examination to improve the quality of the SB image [17, 18]. Patients with bloody stool were examined in the hospital in all cases; based on the time at which the blood stool was noted, the capsule endoscope was able to start testing within a median of $51 \mathrm{~h}$ (inter-quartile range, 24 to $96 \mathrm{~h}$ ). Those who were referred due to anemia had an outpatient examination if there was no bloody stool. To prevent capsule retention, we checked the presence of small bowel stenosis on the CT scan that was performed at least 1 year before the capsule endoscopy. Five gastroenterologists with extensive experience in GI endoscopy reviewed and extensively discussed all capsule video images to reach a diagnosis. An erosion was defined as a roundish area of mucosal disruption smaller than a diameter equivalent to 1 circular fold of the mucosa (also called the valves of Kerckring, valvulae conniventes, or plicae circulares) [19]. An ulcerative lesion was defined as a mucosal penetration with a diameter larger than 1 circular fold of the mucosa [15]. The etiology of ulcerated lesions was determined based on clinical information and endoscopic findings. We examined NSAID-induced enteropathy based on the following criteria: history of NSAID use within the previous 1 month; endoscopic findings, including ulcers, erosions, scar changes, or luminal stenosis; improvement of the clinical course and/or endoscopic findings after cessation of NSAID use; and exclusion of other etiologies, including infection, inflammatory bowel disease, or malignancy [12, 20, 21]. There is no criterion regarding the duration of NSAID use to diagnose NSAID-induced enteropathy. However, because SB injuries were observed in $68 \%$ of healthy volunteers taking NSAIDs for only 1-2 weeks [20, 22], we chose to include patients who had history of NSAID use within the previous 1 month, as was done in a previous study [21].

\section{Statistical analysis}

Continuous variables were compared using Student's $t$-test and categorical variables were analyzed with a chi-square or Fisher's exact test. A two-tailed $p$-value $<0.05$ was considered statistically significant. All statistical analyses were performed using the SPSS statistical package for Windows, Version 24.0 (SPSS Inc., Chicago, IL, USA). 


\section{Results}

\section{Sample analysis}

We assessed 83 subjects (52 men and 31 women) who underwent capsule endoscopy during the study period (see Table 1 for patient characteristics). The subjects were Korean and aged 18-84 years (mean \pm standard deviation: $59 \pm 18$ years). Of these, $55(66.2 \%)$ patients had clear bloody stool and 28 (33.8\%) had normal stool; all had IDA (Fig. 1). The mean small bowel transit time was $6.39 \mathrm{~h}$ (range, 2.42-11.38 h). Capsule retention did not occur in this study. Most patients (92.4\%) showed scores of 3 or 2 on the Boston bowel preparation scale [23]. A total of $37(44.6 \%)$ patients had a history of taking NSAIDs/low-dose aspirin (Table 2). The brand name and dosage of NSAIDs were not clearly identified in the medical records. Musculoskeletal disorders were the most common indication for taking NSAIDs, while coronary artery disease and other cardiovascular diseases were the main indications for taking aspirin. The duration of NSAID use varied from 2 weeks to 10 years prior to the capsule endoscopy. An association with SB bleeding was considered only when NSAIDs/low-dose aspirin was taken within the previous 1 month. Of the 37 patients, 33 had SB lesions; of these, 25 patients were diagnosed with NSAID-induced enteropathy without any other cause of SB bleeding. The main treatments for NSAID-induced enteropathy were discontinuation of NSAIDs or the replacement of NSAIDs with drugs with a low risk of bleeding. Among 37 patients with a history of low-dose aspirin or NSAID medication, only 3 who were treated with selective cyclooxygenase (COX)-2 inhibitors had normal stool. Most patients with active bleeding during endoscopy had angioectasia (8 of 9 patients). A fecal occult blood test was performed in patients with normal stool (16 of 28) and the results were negative in 12 of these patients, among which 7 had no SB lesions. A significantly higher frequency (40 of 51) of ulcerative/erosive lesions was observed in patients with inactive bleeding but visible $\mathrm{SB}$ lesions than other causes; among these patients, 25 had a history of lowdose aspirin or NSAID medication. As a result, NSAIDinduced enteropathy accounted for $30.1 \%$ of 83 patients with obscure GI bleeding (25 of all 60 SB bleeding cases). Four cases of previously undiagnosed Crohn's disease and 1 case of tuberculosis were identified. Other uncommon etiologies associated with unknown GI bleeding included radiation ileitis $(n=3)$ and SB polyps $(n=3)$.

\section{Evaluation of rebleeding and treatment}

Prior to capsule endoscopy, 58 (69.9\%) patients had anemia with hemoglobin $<10 \mathrm{~g} / \mathrm{dL}$. SB bleeding was predominant in $>50 \%$ (17 of 28 ) of patients with normal stool. All patients with SB bleeding due to angioectasia showed bloody stool, while ulcerative lesions were prevalent in patients with normal stool. Rebleeding occurred in 7 patients during the 12-month follow-up period (Table 3). Two patients with Crohn's disease who presented with persistent IDA required specific treatments: One patient was given thiopurine, but the anemia

Table 1 Clinical characteristics of patients

\begin{tabular}{|c|c|c|c|c|}
\hline Characteristic & Overall $(n=83)$ & Bloody stool $(n=55)$ & Normal stool $(n=28)$ & $p$-value \\
\hline Age, yr. & $59 \pm 18$ & $61 \pm 19$ & $56 \pm 15$ & 0.185 \\
\hline Sex, male & $52(62.7)$ & $37(67.3)$ & $15(53.6)$ & 0.222 \\
\hline Aspirin/NSAID & $37(44.6)$ & $25(45.5)$ & $12(42.9)$ & 0.822 \\
\hline Hemoglobin (g/dL) & $8.7 \pm 3.0$ & $8.7 \pm 2.8$ & $8.9 \pm 3.5$ & 0.785 \\
\hline Albumin (g/dL) & $3.8 \pm 0.6$ & $3.7 \pm 0.7$ & $3.9 \pm 0.6$ & 0.191 \\
\hline Small bowel bleeding & $60(72.3)$ & $43(78.2)$ & $17(60.7)$ & 0.093 \\
\hline \multicolumn{5}{|l|}{ Specific lesion ${ }^{a}$} \\
\hline Angioectasia & $14(23.3)$ & $14(32.6)$ & $0(0.0)$ & \\
\hline NSAID-induced & $25(41.7)$ & $15(34.9)$ & $10(58.8)$ & 0.024 \\
\hline enteropathy & $21(35.0)$ & 14 (32.6) & $7(41.2)$ & \\
\hline \multicolumn{5}{|l|}{ Other causes ${ }^{\mathrm{b}}$} \\
\hline \multicolumn{5}{|l|}{ Site of bleeding ${ }^{a}$} \\
\hline Jejunum & $16(26.7)$ & $14(36.2)$ & $2(11.8)$ & \\
\hline Ileum & $38(63.3)$ & $26(60.5)$ & $12(70.6)$ & 0.169 \\
\hline Indeterminate & $6(10.0)$ & $3(7.0)$ & $3(17.6)$ & \\
\hline
\end{tabular}

${ }^{a}$ The denominator is 60 patients with confirmed small bowel lesion

${ }^{b}$ Other causes of small bowel bleeding, including Crohn's disease, intestinal tuberculosis, radiation ileitis, small bowel polyps, and small bowel lesions with unknown causes

Categorical and continuous variables are presented as number (\%) and mean $\pm \mathrm{SD}$, respectively

SD Standard deviation; NSAID Nonsteroidal anti-inflammatory drug; $\mathrm{Hb}$ Hemoglobin 


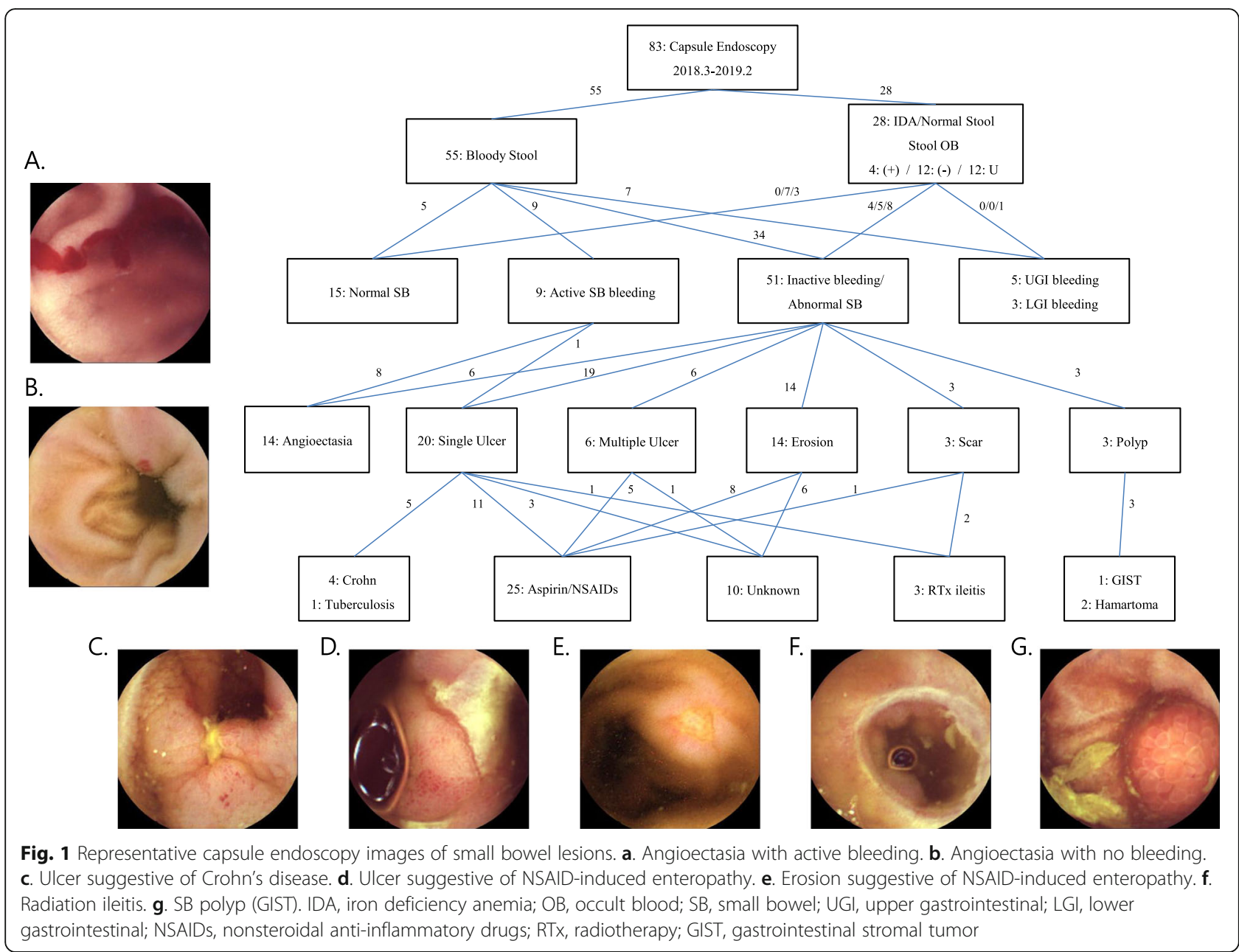

continued and so thiopurine was replaced with methotrexate; no recurrence of anemia has been reported since then. In the other case, administration of immunosuppressive drugs, including thiopurine, failed continuously, mainly due to leukocytopenia associated with persistent IDA; this patient underwent resection of a short segment of the small bowel in which ulcers were observed. After the surgery, anemia has not recurred so far. One patient who was considered to have Crohn's disease initially, presented with multiple lymphadenopathy during the follow-up period and was finally diagnosed with tuberculosis. Among 2 patients with radiation ileitis, 1 underwent surgical treatment due to recurrent life-threatening bloody stool, whereas in the other patient with persistent IDA, medical treatment was continued with prolonged oral iron replacement. A patient with a rebleeding episode from angioectasia received surgery. Lastly, one patient who received NSAIDs to treat fibromyalgia for $>2$ years presented with an ulcerative lesion, had unresolved anemia, and showed recurrent abdominal pain, which lasted for $>6$ months, despite adequate iron administration and stopping NSAIDs. Capsule endoscopy showed multiple small bowel ulcers and an additional abdominal $\mathrm{CT}$ at the recurrence of bleeding revealed multiple strictures of the SB, which was not detected previous $\mathrm{CT}$ scan performed 8 months ago; eventually segmental resection of the SB was performed, through which 5 sites of stenosis in the distal ileum were identified (Fig. 2). No recurrence of anemia or abdominal pain was present 6 months postoperatively.

\section{Discussion}

Capsule endoscopy for unexplained GI bleeding has shown diagnostic yields of $57-62 \%$ [24], with the most common diagnosis being angioectasia $(50 \%)$, followed by ulcers $(26.8 \%)$ and tumors $(8.8 \%)$, as suggested in a recent systematic literature review [14]. The present study revealed a detection rate of SB bleeding and lesions using capsule endoscopy of $72.3 \%$ (60 of 83 patients), of which NSAIDinduced enteropathy accounted for 25 of all 60 SB bleeding cases. The diagnostic yield of small bowel lesions in our study was higher than in a previous nationwide Korean study of capsule endoscopy [25], but the prevalence of ulcerative/erosive lesions was comparable (40/60 vs 106/157). 
Table 2 Details of NSAIDs/low-dose aspirin

\begin{tabular}{|c|c|}
\hline & $\begin{array}{l}N=37(100 \%) \\
(\text { NSAID }=17 / \text { Low-dose } \\
\text { aspirin }=21)^{\mathrm{a}}\end{array}$ \\
\hline \multicolumn{2}{|l|}{ Indication } \\
\hline Coronary artery disease & $11(29.7)$ \\
\hline Other cardiovascular disease & $9(24.3)$ \\
\hline Musculoskeletal disease & $15(40.5)$ \\
\hline Unknown & $3(8.1)$ \\
\hline \multicolumn{2}{|l|}{ Duration } \\
\hline$<1$ month & $2(5.4)$ \\
\hline $1-6$ months & $11(29.7)$ \\
\hline$>6$ months & $22(59.5)$ \\
\hline Unknown & $2(5.4)$ \\
\hline \multicolumn{2}{|l|}{ Concurrent medication } \\
\hline Clopidogrel & $6(16.2)$ \\
\hline Warfarin/NOAC & $7(18.9)$ \\
\hline Other anti-platelet agent & $3(8.1)$ \\
\hline None & $21(56.8)$ \\
\hline \multicolumn{2}{|l|}{ Site of bleeding } \\
\hline Small bowel & $33(89.2)$ \\
\hline Stomach & $2(5.4)$ \\
\hline Undetermined & $2(5.4)$ \\
\hline \multicolumn{2}{|l|}{ Etiology of small bowel bleeding ${ }^{b}$} \\
\hline NSAID-induced enteropathy & $25(75.8)$ \\
\hline Angioectasia & $7(21.2)$ \\
\hline Others & $1(3.0)$ \\
\hline \multicolumn{2}{|c|}{ Initial management of NSAID-induced enteropathy ${ }^{c}$} \\
\hline Discontinue NSAID/low-dose aspirin & $20(80.0)$ \\
\hline Continue NSAID/low-dose aspirin & $2(8.0)$ \\
\hline \multicolumn{2}{|l|}{ + Mucosal protective agent ${ }^{\mathrm{d}}$} \\
\hline Unknown & $3(12.0)$ \\
\hline \multicolumn{2}{|c|}{$\begin{array}{l}\text { a One patient had a history of both NSAID and low dose aspirin } \\
\text { b The denominator is } 33 \text { patients with confirmed small bowel bleeding on } \\
\text { capsule endoscopy } \\
\text { c The denominator is } 25 \text { patients with small bowel bleeding associated with } \\
\text { NSAID/low-dose aspirin } \\
\text { d Mucosal protective agent indicates rebamipide, sucralfate, or } \\
\text { sodium alginate } \\
\text { NSAID, nonsteroidal anti-inflammatory drug; NOAC, non-vitamin K antagonist } \\
\text { oral anticoagulant }\end{array}$} \\
\hline
\end{tabular}

Similar to our results, a Korean study using balloonassisted enteroscopy found that the most common type of SB lesions associated with obscure GI bleeding were mucosal injury (56\%), followed by vascular lesions (18.7\%) [26]. Because of limited availability of data regarding the use of NSAIDs/low-dose aspirin, we could not compare the prevalence of NSAID-induced enteropathy with the results from these studies. However, considering the meaningful association between NSAID use and SB injury presented in previous studies [22, 27], NSAID-induced enteropathy could be the major cause of obscure GI bleeding in Eastern countries. Contrary to previous reports from Western countries, we observed a higher occurrence rate of ulcerative/erosive lesions than angioectasia in patients with obscure GI bleeding, supporting the implication of low-dose aspirin or NSAID medications in the disease etiology. A recent systematic review and meta-analysis suggested that the optical timing of capsule endoscopy would be within 2 days, to improve the diagnostic yield [28]. For patients with clear bloody stool in our study, the capsule endoscope was able to start testing within a median of $51 \mathrm{~h}$ (inter-quartile range, 24 to $96 \mathrm{~h}$ ). In the case of persistent melena or hematochezia enough to show symptoms, the patients usually visited the emergency room and in these patients, the capsule endoscopy could be performed within at least $48 \mathrm{~h}$, but if patients showed intermittent blood stool or if symptoms related to bleeding or anemia were not clear, capsule endoscopy would not be conducted within 2 days. In real practice, further improvement is needed in this respect.

NSAIDs are frequently used anti-inflammatory analgesic agents that represent $7.7 \%$ of worldwide prescriptions, of which $90 \%$ are prescribed to elderly ( $>65$ years) patients [29]. The mechanism of NSAID-induced enteropathy is supposed to be mediated through COX inhibition [30]. Administration of low-dose aspirin (an irreversible nonselective COX inhibitor) is also associated with SB mucosal injuries; large erosions or ulcers were reported in $60 \%$ of healthy volunteers who took $100 \mathrm{mg}$ of low-dose enteric-coated aspirin [31, 32]. In the present study, a history of low-dose aspirin or NSAID use was common in patients with obscure GI bleeding (44.6\%), showing a higher frequency of SB ulcerative lesions than of other sources of lesions (angioectasia, $n=6$; upper or lower GI bleeding, $n=6$ ).

Prostaglandins (PG) play an important role in regulating GI blood flow and mucus production; therefore, NSAID-induced suppression of PG production has been implicated in SB damage [33, 34]. Previously, COX-1 inhibition was regarded to be dominantly related to GI mucosal injuries. However, in a recent animal model study, damage to the SB developed only when both COX-1 and COX-2 were inhibited [35]. This result indicates that COX-2-derived PGs also play an important role in the maintenance of tissue integrity and repair of mucosal injury. However, clinical research has shown conflicting results. Several studies have shown an improved GI safety profile with selective COX-2 inhibitors compared to nonselective NSAIDs [36, 37], while others studies indicated no significant differences in SB injuries between these NSAIDs [38, 39]. In the current study, among 37 patients with a history of low-dose aspirin or NSAID medications, the 3 treated with selective COX-2 inhibitors had normal stool, suggesting favorable GI outcomes with selective COX-2 inhibitor therapy. Considering 
Table 3 Rebleeding cases

\begin{tabular}{|c|c|c|c|c|c|c|}
\hline No. & $\begin{array}{l}\text { Indication for capsule } \\
\text { endoscopy }\end{array}$ & $\begin{array}{l}\text { Cause of small bowel } \\
\text { bleeding }\end{array}$ & Final diagnosis & $\begin{array}{l}\text { Timing of rebleeding } \\
\text { after diagnosis }\end{array}$ & Specific therapy & Treatment outcome \\
\hline 1 & Bloody stool & Ulcer & Crohn's disease & 23 days & Thiopurine & Persistent IDA ${ }^{c}$ \\
\hline 2 & Bloody stool & Diffuse scar change & Radiation ileitis $^{a}$ & 87 days & Surgery & No further bleeding \\
\hline 3 & Bloody stool & Ulcer & Crohn's disease & 117 days & 5-aminosalicylic acid & Persistent IDA ${ }^{c}$ \\
\hline 4 & Bloody stool & Ulcer with stricture & Radiation ileitis $^{\mathrm{a}}$ & 49 days & Iron replacement & Follow-up loss \\
\hline 5 & IDA & Ulcer & Intestinal Tbc ${ }^{\mathrm{b}}$ & 146 days & Anti-Tbc medication & Recovered IDA \\
\hline 6 & IDA & Ulcer with stricture & NSAID-induced enteropathy & 15 days & Surgery & Recovered IDA \\
\hline 7 & Bloody stool & Angioectasia & Angioectasia & 330 days & Surgery & No further bleeding \\
\hline
\end{tabular}

a Indication for radiation therapy was uterine cervical cancer

${ }^{b}$ The patient who was considered as having Crohn's disease initially, presented with multiple lymphadenopathy and was finally diagnosed with tuberculosis 'Patient No.1 was given methotrexate instead of thiopurine and no recurrence of anemia has been reported since then; Patient No.3 underwent resection of a short segment of the small bowel and anemia has not recurred so far

IDA Iron deficiency anemia; Tbc Tuberculosis; NSAID Nonsteroidal anti-inflammatory drug

that selective COX-2 inhibitors are not completely safe for the $\mathrm{SB}$, further long-term studies with a larger sample size are warranted to establish the safety profile of the drug in the SB.

Furthermore, the impact of capsule endoscopy on clinical outcomes remains controversial despite reports of SB mucosal damage in $70 \%$ of patients taking NSAIDs $[22,40]$, because it remains unclear whether SB mucosal injuries contribute to significant bleeding [41]. Although patients with NSAID-induced SB injury show low frequency of severe bleeding in the SB [42], rebleeding rates of $21-35 \%$ have been reported in patients with SB ulcerations during a mean follow-up period of 17.129.7 months $[15,43]$. These reports suggest a clinical implication of SB ulcers, which cannot be ignored.

The most effective method of preventing NSAIDinduced enteropathy is discontinuation of NSAIDs if possible [12]. Previously, there was no strategy to prevent NSAID-induced enteropathy [13, 44]. However, a recent study reported the effectiveness of misoprostol in the treatment of SB ulcer bleeding associated with aspirin [45]. On the contrary, lesions that induce stenosis,
A.

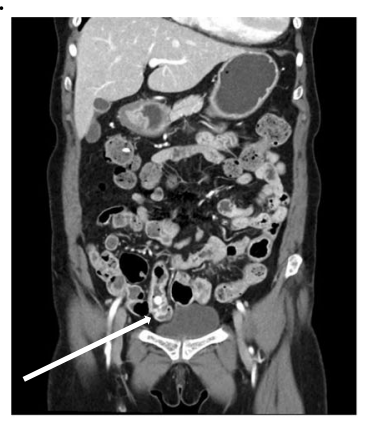

D.

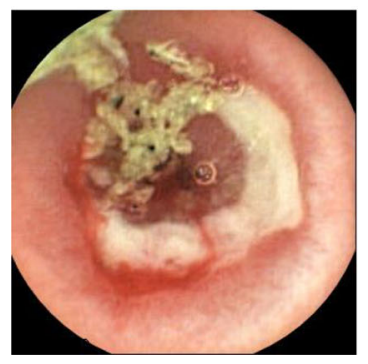

B.

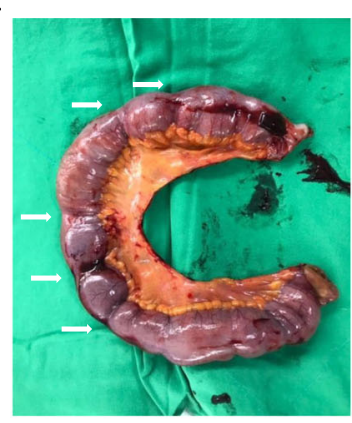

E.

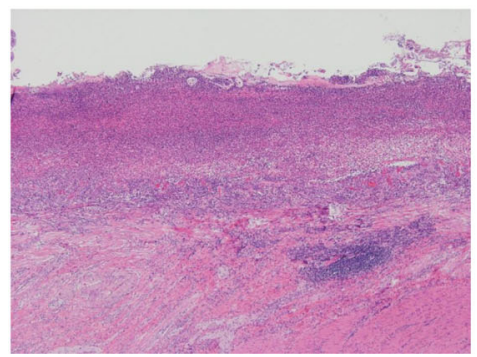

Fig. 2 Surgical intervention in a patient with small-bowel stricture. a. Abdominal computed tomography showing a stricture in the distal ileum. b. Gross findings after bowel resection with multiple stricture sites. c. Surgical resection exposing the inside of the small bowel. d. Capsule endoscopy image showing a semi-circular ulcer with active hemorrhage. e. Histologic findings show ulceration including diffuse loss of villi, mucosal and submucosal neutrophilic exudates, and transmural inflammation (Hematoxylin and Eosin $\times 40$ ) 
which may not be treated with medication alone, require endoscopic or surgical interventions [46]. In the present study, a patient suffering from fibromyalgia developed SB stricture after NSAID medications for $>2$ years and eventually underwent surgical resection.

This study has several limitations. First, it was a retrospective analysis with a small sample size, with insufficient power to detect a significant effect. Second, because balloon-assisted enteroscopy was not routinely performed, pathological findings could not confirm SB ulcers. Third, the short follow-up period prevented the adequate assessment of risk factors for rebleeding. Finally, the fecal occult blood test could not be performed in 12 of 28 patients who presented with normal stool, thereby limiting the interpretation of the results.

\section{Conclusions}

This study showed an improved diagnostic yield of capsule endoscopy for obscure GI bleeding and reaffirmed that NSAID-induced enteropathy is the most common etiology of SB bleeding in Korean patients. Therefore, aggressive clinical management, including SB capsule endoscopy, should be considered for patients with unexplained GI bleeding or drug-refractory iron deficiency anemia, particularly during aspirin or NSAID medications.

\section{Abbreviations}

Gl: Gastrointestinal; SB: Small bowel; NSAIDs: Nonsteroidal anti-inflammatory drugs; COX: Cyclooxygenase; PG: Prostaglandin; CT: Computed tomography

\section{Acknowledgements}

Not Applicable.

\section{Authors' contributions}

Study coordination and drafting of the manuscript: DHL and KJ. Study coordination and critical review of the manuscript: DHL and LSB. Review of capsule endoscopy images: KJ, LSB, JHP, JHK, and SEK. Data supply and approval of the final version of this manuscript: IKP, HJC, BGK, IDJ, and MW. Data analysis and approval of the final version of this manuscript: SWJ, MIP, and SJP. All authors read and approved the final manuscript.

\section{Funding}

No funding was obtained for the study.

\section{Availability of data and materials}

The datasets used and/or analyzed during the current study are available from the corresponding author on request.

\section{Ethics approval and consent to participate}

This study was approved by the Institutional Review Board (IRB, the local ethical committee) of the Ulsan University Hospital (IRB No. 2019-10-014) and the Kosin University Gospel Hospital (IRB No. 2019-10-001).

\section{Consent for publication}

Not applicable. The requirement for informed consent from patients was waived by the IRB because patient records and information were deidentified.

\section{Competing interests}

The authors declare no competing interests.

\section{Author details}

'Department of Internal Medicine, University of Ulsan College of Medicine, Ulsan University Hospital, 877 Bangeojinsunhwando-ro, Dong-gu, Ulsan 44033, South Korea. ${ }^{2}$ Department of Internal Medicine, Kosin University College of Medicine, Kosin University Gospel Hospital, Busan, South Korea. ${ }^{3}$ Department of General Surgery, University of Ulsan College of Medicine, Ulsan University Hospital, Ulsan, South Korea. ${ }^{4}$ Department of Pathology, University of Ulsan College of Medicine, Ulsan University Hospital, Ulsan, South Korea.

Received: 20 February 2020 Accepted: 1 June 2020

Published online: 08 June 2020

\section{References}

1. Leighton JA, Goldstein J, Hirota W, et al. Obscure gastrointestinal bleeding. Gastrointest Endosc. 2003;58:650-5.

2. Singh A, Baptista $V$, Stoicov $C$, et al. Evaluation of small bowel bleeding. Curr Opin Gastroenterol. 2013;29:119-24.

3. Gerson LB, Fidler JL, Cave DR, et al. ACG clinical guideline: diagnosis and Management of Small Bowel Bleeding. Am J Gastroenterol. 2015;110:126587 quiz 1288

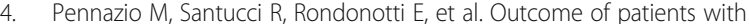
obscure gastrointestinal bleeding after capsule endoscopy: report of 100 consecutive cases. Gastroenterology. 2004;126:643-53.

5. Raju GS, Gerson L, Das A, et al. American Gastroenterological Association (AGA) institute technical review on obscure gastrointestinal bleeding. Gastroenterology. 2007;133:1697-717.

6. Iddan G, Meron G, Glukhovsky A, et al. Wireless capsule endoscopy. Nature. 2000;405:417.

7. Saurin JC, Delvaux M, Gaudin JL, et al. Diagnostic value of endoscopic capsule in patients with obscure digestive bleeding: blinded comparison with video push-enteroscopy. Endoscopy. 2003;35:576-84.

8. Ell C, Remke S, May A, et al. The first prospective controlled trial comparing wireless capsule endoscopy with push enteroscopy in chronic gastrointestinal bleeding. Endoscopy. 2002:34:685-9.

9. Yamamoto H, Kita H, Sunada K, et al. Clinical outcomes of double-balloon endoscopy for the diagnosis and treatment of small-intestinal diseases. Clin Gastroenterol Hepatol. 2004;2:1010-6.

10. Niikura R, Yamada A, Nagata N, et al. New predictive model of rebleeding during follow-up of patents with obscure gastrointestinal bleeding: a multicenter cohort study. J Gastroenterol Hepatol. 2016;31:752-60.

11. Sostres C, Gargallo CJ, Lanas A. Nonsteroidal anti-inflammatory drugs and upper and lower gastrointestinal mucosal damage. Arthritis Res Ther. 2013; 15(Suppl 3):-S3.

12. Shin SJ, Noh CK, Lim SG, et al. Non-steroidal anti-inflammatory druginduced enteropathy. Intest Res. 2017;15:446-55.

13. Lim YJ, Yang CH. Non-steroidal anti-inflammatory drug-induced enteropathy. Clin Endosc. 2012;45:138-44.

14. Liao Z, Gao R, Xu C, et al. Indications and detection, completion, and retention rates of small-bowel capsule endoscopy: a systematic review. Gastrointest Endosc. 2010;71:280-6.

15. Aoki T, Yamada A, Hirata Y, et al. Etiology and long-term rebleeding of endoscopic ulcerative lesions in the small bowel in patients with obscure gastrointestinal bleeding: a multicenter cohort study. J Gastroenterol Hepatol. 2018;33:1327-34.

16. Albert J, Gobel CM, Lesske J, et al. Simethicone for small bowel preparation for capsule endoscopy: a systematic, single-blinded, controlled study. Gastrointest Endosc. 2004;59:487-91.

17. Yang L, Wang X, Gan T, et al. Polyethylene glycol for small bowel capsule endoscopy. Gastroenterol Res Pract. 2017;2017:7468728.

18. Dai N, Gubler C, Hengstler P, et al. Improved capsule endoscopy after bowel preparation. Gastrointest Endosc. 2005;61:28-31.

19. Graham DY, Opekun AR, Willingham FF, et al. Visible small-intestinal mucosal injury in chronic NSAID users. Clin Gastroenterol Hepatol. 2005;3: 55-9.

20. Hayashi $\mathrm{Y}$, Yamamoto $\mathrm{H}$, Kita $\mathrm{H}$, et al. Non-steroidal anti-inflammatory druginduced small bowel injuries identified by double-balloon endoscopy. World J Gastroenterol. 2005;11:4861-4.

21. Matsumoto T, Kudo T, Esaki M, et al. Prevalence of non-steroidal antiinflammatory drug-induced enteropathy determined by double-balloon 
endoscopy: a Japanese multicenter study. Scand J Gastroenterol. 2008;43: 490-6.

22. Maiden $L$, Thjodleifsson $B$, Theodors $A$, et al. A quantitative analysis of NSAID-induced small bowel pathology by capsule enteroscopy. Gastroenterology. 2005;128:1172-8.

23. Lai EJ, Calderwood AH, Doros G, et al. The Boston bowel preparation scale: a valid and reliable instrument for colonoscopy-oriented research. Gastrointest Endosc. 2009;69:620-5.

24. Xin L, Liao Z, Jiang YP, et al. Indications, detectability, positive findings, total enteroscopy, and complications of diagnostic double-balloon endoscopy: a systematic review of data over the first decade of use. Gastrointest Endosc. 2011;74:563-70.

25. Min YW, Kim JS, Jeon SW, et al. Long-term outcome of capsule endoscopy in obscure gastrointestinal bleeding: a nationwide analysis. Endoscopy. 2014:46:59-65.

26. Jeon SR, Kim JO, Kim HG, et al. Changes over time in indications, diagnostic yield, and clinical effects of double-balloon enteroscopy. Clin Gastroenterol Hepatol. 2012;10:1152-6.

27. Maiden L. Capsule endoscopic diagnosis of nonsteroidal antiinflammatory drug-induced enteropathy. J Gastroenterol. 2009;44(Suppl 19):64-71.

28. Uchida G, Nakamura M, Yamamura T, et al. Systematic review and metaanalysis of the diagnostic and therapeutic yield of small bowel endoscopy in patients with overt small bowel bleeding. Dig Endosc. 2020. [Epub ahead of print].

29. Tai FWD, McAlindon ME. NSAIDs and the small bowel. Curr Opin Gastroenterol. 2018;34:175-82.

30. Davies NM, Saleh JY, Skjodt NM. Detection and prevention of NSAIDinduced enteropathy. J Pharm Pharm Sci. 2000;3:137-55.

31. Iwamoto J, Mizokami Y, Saito Y, et al. Small-bowel mucosal injuries in lowdose aspirin users with obscure gastrointestinal bleeding. World J Gastroenterol. 2014;20:13133-8.

32. Shiotani A, Haruma K, Nishi R, et al. Randomized, double-blind, pilot study of geranylgeranylacetone versus placebo in patients taking low-dose enteric-coated aspirin. Low-dose aspirin-induced small bowel damage. Scand J Gastroenterol. 2010;45:292-8.

33. Robert A, Asano T. Resistance of germfree rats to indomethacin-induced intestinal lesions. Prostaglandins. 1977;14:333-41.

34. Fang WF, Broughton A, Jacobson ED. Indomethacin-induced intestinal inflammation. Am J Dig Dis. 1977;22:749-60.

35. Sigthorsson G, Simpson RJ, Walley M, et al. COX-1 and 2, intestinal integrity, and pathogenesis of nonsteroidal anti-inflammatory drug enteropathy in mice. Gastroenterology. 2002;122:1913-23.

36. Mizukami K, Murakami K, Yamauchi M, et al. Evaluation of selective cyclooxygenase-2 inhibitor-induced small bowel injury: randomized crossover study compared with loxoprofen in healthy subjects. Dig Endosc. 2013; 25:288-94.

37. Inoue T, lijima $\mathrm{H}$, Arimitsu J, et al. Amelioration of small bowel injury by switching from nonselective nonsteroidal anti-inflammatory drugs to celecoxib in rheumatoid arthritis patients: a pilot study. Digestion. 2014;89: 124-32.

38. Maiden L, Thjodleifsson B, Seigal A, et al. Long-term effects of nonsteroidal anti-inflammatory drugs and cyclooxygenase-2 selective agents on the small bowel: a cross-sectional capsule enteroscopy study. Clin Gastroenterol Hepatol. 2007;5:1040-5.

39. Maehata Y, Esaki M, Morishita T, et al. Small bowel injury induced by selective cyclooxygenase-2 inhibitors: a prospective, double-blind, randomized clinical trial comparing celecoxib and meloxicam. J Gastroenterol. 2012;47:387-93.

40. Maiden L, Elliott T, McLaughlin SD, et al. A blinded pilot comparison of capsule endoscopy and small bowel histology in unresponsive celiac disease. Dig Dis Sci. 2009;54:1280-3.

41. Niikura R, Yamada A, Maki K, et al. Associations between drugs and smallbowel mucosal bleeding: multicenter capsule-endoscopy study. Dig Endosc. 2018;30:79-89

42. Chan FK, Lanas A, Scheiman J, et al. Celecoxib versus omeprazole and diclofenac in patients with osteoarthritis and rheumatoid arthritis (CONDOR): a randomised trial. Lancet. 2010;376:173-9.

43. Shinozaki S, Yamamoto H, Yano T, et al. Long-term outcome of patients with obscure gastrointestinal bleeding investigated by double-balloon endoscopy. Clin Gastroenterol Hepatol. 2010;8:151-8.
44. Park SC, Chun HJ, Kang CD, et al. Prevention and management of nonsteroidal anti-inflammatory drugs-induced small intestinal injury. World J Gastroenterol. 2011;17:4647-53.

45. Kyaw MH, Otani K, Ching JYL, et al. Misoprostol heals small bowel ulcers in aspirin users with small bowel bleeding. Gastroenterology. 2018;155:1090-7 e1.

46. Slesser AA, Wharton R, Smith GV, et al. Systematic review of small bowel diaphragm disease requiring surgery. Color Dis. 2012;14:804-13.

\section{Publisher's Note}

Springer Nature remains neutral with regard to jurisdictional claims in published maps and institutional affiliations.
Ready to submit your research? Choose BMC and benefit from:

- fast, convenient online submission

- thorough peer review by experienced researchers in your field

- rapid publication on acceptance

- support for research data, including large and complex data types

- gold Open Access which fosters wider collaboration and increased citations

- maximum visibility for your research: over $100 \mathrm{M}$ website views per year

At BMC, research is always in progress.

Learn more biomedcentral.com/submissions 